\title{
Prognostic value of frontal QRST angle and in hospital outcome in ST- Segment Elevation Myocardial Infarction patients undergoing primary percutaneous coronary angioplasty
}

\author{
Arjun Budhathoki ${ }^{1,2}$, Arun Maskey ${ }^{2}$, Rabi Malla ${ }^{2}$, Sujeeb Rajbhandari' ${ }^{2}$, Dipika Basnet ${ }^{3}$, \\ Rabindra Simkhada ${ }^{2}$, Rikesh Tamrakar ${ }^{2}, K_{r i s h n a}$ Chandra Adhikari ${ }^{1,2}$, Bishal Shrestha ${ }^{1,2}$, \\ Chitra Raj Sharma ${ }^{1,2}$, Manoj Koirala ${ }^{1,2}$, Shreya Bhandari², Shipra Shrestha ${ }^{2}$, Bishow Raj Baral ${ }^{1,2}$ \\ ${ }^{1}$ Department of Cardiology, National Academy of Medical Sciences, Mahaboudhha, Kathmandu. \\ ${ }^{2}$ Department of Cardiology, Shahid Gangalal National Heart Centre, Bansbari, Kathmandu. \\ ${ }^{3}$ Department of Pathology, Kathmandu University School of Medical Sciences, Dhulikhel, Kavre.
}

\author{
Corresponding Author: Arjun Budhathoki \\ Department of Cardiology, National Academy of Medical Sciences Kathmandu, Nepal. \\ E-mail: arjun.k.bud@gmail.com
}

ORCID ID NO: 0000-0003-4356-3439

Cite this article as: Budhathoki A., Maskey A., Malla R., et al. Prognostic value of frontal QRST angle and in hospital outcome in ST- Segment Elevation Myocardial Infarction patients undergoing primary percutaneous coronary angioplasty. Nepalese Heart Journal 2021; Vol 18(2), 21-25.

Submission date: $26^{\text {th }}$ June, 2021

Accepted date: $16^{\text {th }}$ September, 2021

\section{Abstract}

Background and Aims: Frontal QRS-T angle has been previously correlated with long term mortality in ST-segment elevation myocardial infarction patients. This study aimed to investigate the prognostic value of frontal QRS-T angle and in-hospital outcomes in the setting of ST-segment elevation myocardial infarction patients undergoing primary percutaneous coronary intervention.

Methods: We evaluated 97 consecutive patients presenting to the emergency department of Shahid Gangalal National Heart Centre with chest pain of less than 12 hours duration, who were subsequently diagnosed as ST-segment elevation myocardial infarction in a prospective observational study. The study was conducted from July 2020 to June 2021. The data evaluation included demographics, clinical variables, electrocardiogram, length of hospital stay and in hospital mortality. Patient outcomes were stratified into three groups according to frontal QRS-T angle. The relationship between mortality and frontal QRS-T angle was tested with chi-square test. The p-value across the groups was again tested for inter-group significance.

Results: Out of 97 patients $67(69.07 \%)$ were male and 30(30.92\%) were female., The mean age of study population was $55.8 \pm 11.8$ years. The patients under study were divided into three groups based on the calculation of fQRST angle as Group 1 $\left(0-45^{\circ}\right)$ being $46(47.4 \%)$, Group $2\left(46-90^{\circ}\right)$ being $20(20.6 \%)$ and Group $3\left(>90^{\circ}\right)$ with $31(32 \%)$ cases. Diabetes and Congestive heart failure (CHF) patients were more likely to have increase in frontal QRST angle ( $\mathrm{p}$ value $0.029,0.012$ respectively). Atrial fibrillation (AF)was higher among patients in group 3( $>90^{\circ}$ frontal QRST angle) which was statistically significant $(0.012)$. Although the mean length of hospital stay was higher among patients with highest frontal QRST angle, it was statistically insignificant ( $p$ value 0.062 ). However, the chance of hospital stay duration significantly increased across three groups at a $5 \%$ significance level (p-value: 0.018). In hospital mortality increased with increase in frontal QRST angle with 8.7\%, 15\% and $22.6 \%$ in group 1, 2 and 3 respectively; however it was statistically insignificant.

Conclusion: Diabetes, CHF and AF patients were more likely to have increase in frontal QRST angle. The chance of hospital stay duration significantly increases with increase in frontal QRST angle. Although the in hospital mortality increased with increase in the frontal QRST angle, it was statistically insignificant. A prospective study with larger sample size will help to clarify its association.

Keywords: acute ST elevation myocardial infarction; frontal QRST angle; in-hospital mortality; primary percutaneous coronary angioplasty

DOI: https://doi.org/10.3126/njh.v18i2.40396

\section{Introduction}

Acute ST elevation Myocardial Infarction ( STEMI ) has a high mortality despite primary percutaneous coronary intervention (PPCI) which is the recommended revascularization strategy to reduce cardiovascular death ${ }^{1}$. Different electrocardiogram (ECG) parameters have been utilized to determine high-risk patients during an acute STEMI1, ${ }^{2,3}$. QRS duration, T- wave loop dispersion, $\mathrm{R}$ to $\mathrm{T}$ total cosine (measure of repolarization) and QRST angle can be used to risk stratify patients after myocardial infarction ${ }^{4-6}$.

Vectorcardiography (VCG) visualizes movement of the heart vector through cardiac cycle as loops. Depolarization is denoted by QRS loop while T loop reflects repolarization. Spatial QRS-T angle 
is the angle between spatial $\mathrm{QRS}$ vector and spatial $\mathrm{T}$ vector which can be obtained by $\mathrm{VCG}^{7}$. An abnormally wide QRS-T angle has emerged as a prominent variable in stratifying cardiac risk which has also been shown to be associated with higher mortality in the general population $^{7,8}$. Spatial QRS-T angle is not routinely measured on 12 lead ECGs, however specialized software can be incorporated into ECG machines to calculate it. Alternatively, frontal QRST(fQRST) angle can be calculated from a routine 12-lead ECG and does not require specialized software. Recent studies have identified the fQRST angle as a useful ECG measure of the dispersion between depolarization and repolarization ${ }^{8}$. Frontal and spatial QRS-T angles are comparable and have a strong correlation ${ }^{9}$. A wider fQRST angle is a strong and independent risk indicator for cardiac morbidity and mortality compared to other traditional cardiovascular risk factors and ECG risk indicators ${ }^{10}$.

The fQRST angle can help triage patients and help in the prompt and better management of patients ${ }^{11}$. There have been no studies conducted in our country regarding the correlation between fQRST angle and STEMI patients undergoing PPCI. This study will highlight upon the prognostic value of fQRST angle and provide an understanding of the impact of it on the risk of in hospital outcomes in patients with STEMI.

\section{Methods}

Our study was a hospital based, prospective, observational study. It was conducted at Shahid Gangalal National Heart Center, Bansbari, Kathmandu through June 2020 to July 2021 for a period of 1 year. Ethical clearance was formally taken from Institute Review Board, National Academy of Medical Sciences, Mahabouddha, Kathmandu.

The sample size was calculated by using the formula $\mathrm{N}=\mathrm{Z} 2 \times \mathrm{p}$ $\mathrm{x} q / \mathrm{e} 2$ where, $\mathrm{p}=$ prevalence, $\mathrm{e}$ is the desired level of precision (i.e. the margin of error), $p$ is the (estimated) proportion of the population which has the attribute in question (the prevalence of STEMI in all the studies mentioned in the literatures varied between $4 \%$ to $10 \%$. For this study, highest prevalence percentage is taken, i.e., $10 \%$ )

$\mathrm{q}$ is $1-\mathrm{p}, \mathrm{q}=100-\mathrm{p}=100-10=90 \%$

$\mathrm{Z}=$ Confidence level at $95 \%=1.64, \mathrm{e}=$ range of $\mathrm{CI}=5 \%$

$: \mathrm{N}=\mathrm{Z} 2 \times \mathrm{p} \times \mathrm{q} / \mathrm{e} 2$

$(1.64) 2 \times 10 \times 90 / 52=2.68 \times 10 \times 90 / 25=2.68 \times 900 / 25=$ 96.48 97

\section{Sample Technique}

All consecutive patients above 18 years with acute ST Elevation myocardial infarction (STEMI) who presented within 12 hours of symptoms onset were included in the study. ST Elevation Myocardial Infarction was defined according to the American College of Cardiology (ACC)guidelines on Universal Definition of Myocardial Infarction ${ }^{12}$. Patients with past history of CAD or MI, PCI, CABG or any cardiac surgery, severe valvular heart disease, cardiomyopathy, preexisting renal or hepatic disease, acute infection, HIV infection, concomitant disease eg, connective tissue disorder, consuming cardiotoxic drugs like chemotherapy or immunomodulators, complete and incomplete right or left bundle branch block, pacemaker rhythm or left ventricular hypertrophy by ECG were excluded from the study.

Written informed consent was taken from the patient or relative. Plan and purpose of the study was clearly explained. A 12 lead Electrocardiogram (ECG) was obtained at the emergency room of Shahid Gangalal National Heart Centre within 10 minutes of arrival and was interpreted by two senior residents with the patient in the supine resting position using a ECG Machine (Philips Medical Systems, Andover, MA, USA). The ECGs were obtained using Nihon Kohden CardiofaxM (Nihon Kohden Corporation, Tokyo, Japan)at a paper speed of $25 \mathrm{~mm}$ and a gain of $10 \mathrm{mV}$. ECG variables including heart rate, PR interval, QRS duration, QRS axis, and $\mathrm{T}$-wave axis were collected. The fQRST angle was calculated as the absolute difference between the frontal QRS and frontal T-wave axis calculated as T-wave axis - QRS axis. If the angle was greater than 180 o, the difference was subtracted from 360 o to obtain a continuous variable ranging from $0 \mathrm{o}$ to $180 \mathrm{o} 11$. Patients were allocated into 3 groups according to the fQRST angle based on the relative risk associated with increasing values of fQRST,11 Group 1:f QRST angle (0o-45o); Group 2: fQRST angle (46o-90o); Group 3: fQRST angle $(>90 \mathrm{o})$. In addition to ECG data, demographics, risk factors and hematocrit were also obtained. All patients had PPCI after coronary angiogram, the findings of which were noted. Each patient was followed until discharge and the length of hospital stay was noted. The outcomes of the treatment were recorded as in-hospital mortality. In-hospital mortality was defined as the mortality of the patient during the index hospitalization. Each patient was followed during the hospital stay.

\section{Statistical Analysis}

Data was then entered into spread sheet (Microsoft Excel) and the statistical analysis was done using the Statistical Package for the Social Science (SPSS) software. Continuous variables were listed as mean \pm standard deviation and categorical variables were presented as number, proportions or percentages. After processing of all available information, statistical analysis of their significance was done. The differences in their means were analyzed with MannWhitney U-test. The relationship between mortality and frontal QRS-T angle was tested with chi-square test. The p-value across the groups was again tested for inter-group significance. The statistical significance was considered as $\mathrm{P}<0.05$.

\section{Results}

In this study, a total of 97 patients were included. The age of the patients ranged from 25 years to 77 years, the mean age being $55.8 \pm 11.8$ years. Of the total patients, $67(69.1 \%)$ were males and $30(30.9 \%)$ were females. The patients under study were divided into three groups based on the calculation of fQRST angle as Group 1 (0450 ) being 46(47.4\%), Group 2(46-900) being 20(20.6\%) and Group 3 (>900) with $31(32 \%)$ cases.

Out of 97 patients $67(69.0 \%)$ were male and 30(30.9\%) were female. There was no relationship of fQRST angle with age. Male gender had increased association with STEMI with an increase in fQRST angle but was not statistically significant (Table 1).

Table 1. Demographics and clinical characteristics

\begin{tabular}{|l|c|c|c|c|}
\hline Variable & $\begin{array}{c}\text { Group 1 } \\
\text { FQRST } \\
\text { angle 0-450 } \\
(\mathrm{n}=46)\end{array}$ & $\begin{array}{c}\text { Group 2 } \\
\text { FQRST } \\
\text { angle 46- } \\
900(\mathrm{n}=20)\end{array}$ & $\begin{array}{c}\text { Group 3 } \\
\text { FQRST } \\
\text { angle }>900 \\
(\mathrm{n}=31)\end{array}$ & p-value \\
\hline $\begin{array}{l}\text { Demographics } \\
\text { Age }\end{array}$ & $58.0 \pm 11.8$ & $54.7 \pm 10.7$ & $58.9 \pm 10.9$ & 0.421 \\
\hline $\begin{array}{l}\text { Male gender } \\
\text { Clinical variables } \\
\text { Diabetes type 2 }\end{array}$ & $31(67.4 \%)$ & $14(70 \%)$ & $22(71 \%)$ & 0.941 \\
\hline $\begin{array}{l}\text { Smoking } \\
\text { Hypertension }\end{array}$ & $26(56.5 \%)$ & $9(45 \%)$ & $17(54.8 \%)$ & 0.680 \\
\hline $\begin{array}{l}\text { Hyperlipidemia } \\
\text { Family History of } \\
\text { CAD }\end{array}$ & $25(53.3 \%)$ & $11(55 \%)$ & $20(64.5 \%)$ & 0.650 \\
\hline \begin{tabular}{l} 
CHF \\
\hline Laboratory data
\end{tabular} & $3(17.4 \%)$ & $7(35 \%)$ & $3(9.7 \%)$ & $0.084 \mathrm{~L}$ \\
\hline Hematocrit $(\%)$ & $39.2 \pm 3.3$ & $40.2 \pm 4.0$ & $40.2 \pm 4.8$ & 0.491 \\
\hline
\end{tabular}




\begin{tabular}{|c|c|c|c|c|}
\hline $\begin{array}{l}\text { Electrocardiographic } \\
\text { data } \\
\text { Heart rate(beats } / \mathrm{min} \text { ) }\end{array}$ & $98.2 \pm 21.1$ & $\begin{array}{c}107.95 \pm \\
24.26\end{array}$ & $\begin{array}{c}101.48 \pm \\
22.37\end{array}$ & 0.265 \\
\hline PR Interval(ms) & $\begin{array}{c}143.91 \pm \\
35.682\end{array}$ & $151 \pm 80.12$ & $\begin{array}{c}123.87 \pm \\
86.32\end{array}$ & 0.279 \\
\hline QRS duration (ms) & $99.1 \pm 16.3$ & $169 \pm 46.55$ & $\begin{array}{l}132.9 \pm \\
35.232\end{array}$ & $<0.001$ \\
\hline Atrial fibrillation & $3(6.5 \%)$ & $3(15 \%)$ & $10(32.3 \%)$ & 0.012 \\
\hline
\end{tabular}

Patients with higher fQRST angle were more likely to have diabetes and congestive heart failure which was statistically significant with a p-value of 0.029 and 0.012 respectively. A similar increase frequency of hypertension (67.7\%) and hyperlipidaemia $(64.5 \%)$ was seen in patients in group 3 with higher fQRST angle, however, was not statistically significant. Smoking and family history of coronary artery disease did not differ between the three fQRST groups (Table 1).

Heart rate, PR interval and hematocrit also did not show a statistically significant difference between the three fQRST groups (Table 1). QRS duration and incidence of atrial fibrillation were higher among patients in group 3 which was statistically significant (Table 1).

On coronary angiographic study, greater frequency of multivessel disease (double vessel disease and triple vessel disease) was seen in patients with higher fQRST angle, $\mathrm{p}$-value $=0.05$ (Figure 1).

Figure 1. Distribution of Angiographic findings based on fQRST angle

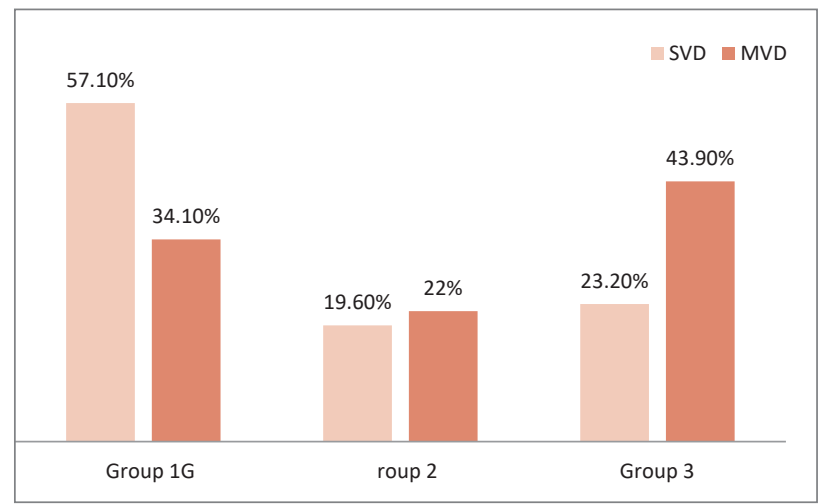

The mean length of hospital stay was higher among patients with the highest fQRST angle but was not statistically significant (Table 2). In-hospital mortality increased with an increase in fQRST angle with $8.7 \%, 15 \%$ and $22.6 \%$ in group 1,2 and 3 respectively (Table 2).

Table 2. Outcomes-based on fQRST angle

\begin{tabular}{|l|c|c|c|c|}
\multicolumn{1}{|c|}{ Outcomes } & Group 1 & Group 2 & Group 3 & p-value \\
\hline $\begin{array}{l}\text { Length of } \\
\text { hospital } \\
\text { stay(days) }\end{array}$ & $6.3 \pm 1.8$ & $6.9 \pm 2.9$ & $7.7 \pm 2.7$ & 0.062 \\
\hline $\begin{array}{l}\text { Death(In hospital } \\
\text { mortality) }\end{array}$ & $4(8.7 \%)$ & $3(15 \%)$ & $7(22.6 \%)$ & 0.235 \\
\hline
\end{tabular}

The table shows that the length of hospital stay is comparatively higher in group $3(7.7 \pm 2.7)$ with a high per cent of mortality $(22.6 \%)$. However, the differences in duration of hospital stay (p-value:0.062) and morality (p-value:0.235) are statistically insignificant among groups at $95 \%$ confidence level.
Figure 2. Kaplan-Meier curves

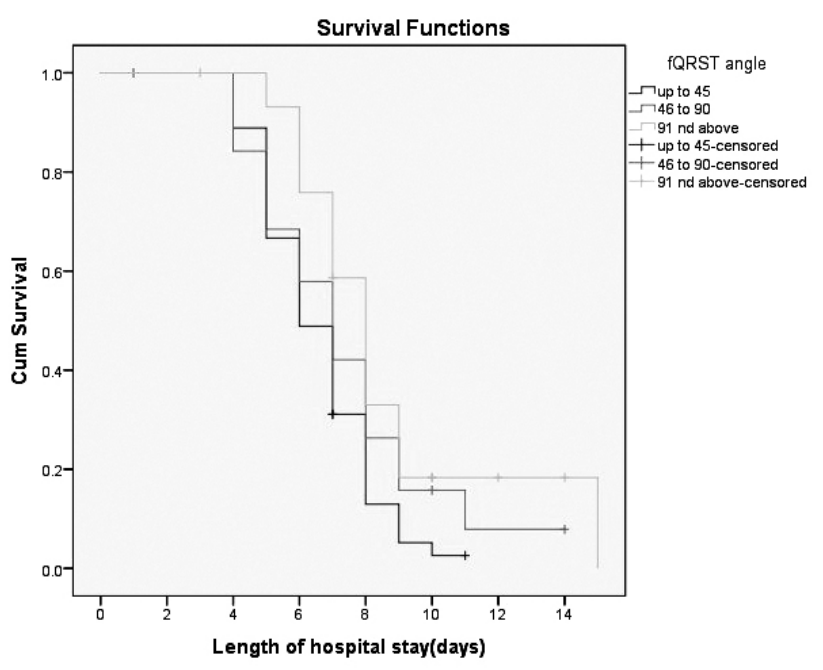

The figure 2 is the Kaplan-Meier curves for the cumulative risk of hospital stay across the three groups. It shows that the chance of hospital stay durations significantly increases across three groups at a 5\% significance level (p-value: 0.018). These differences in risk increase in hospital stay were confirmed using Breslow (Generalized Wilcoxon) test (see Table 3).

Table 3. Overall comparison

\begin{tabular}{|l|c|c|c|}
\hline & Chi-Square & Df & Sig. \\
\hline $\begin{array}{l}\text { Breslow } \\
\text { (Generalized } \\
\text { Wilcoxon) }\end{array}$ & 8.066 & 2 & 0.018 \\
\hline
\end{tabular}

Test of equality of survival distributions for the different levels of fQRST angle.

\section{Discussion}

This study assessed the utility of fQRST angle obtained from point of care 12 lead ECG for risk stratification in STEMI patients undergoing PPCI. Gender differences in fQRST angle were present in our study. Male gender presenting with STEMI had increased fQRST angle than their female counterparts. However this was not statistically significant. Similar findings were observed by Lingman et al and Sur et al1 $1^{3,14}$. The reason for the disparity in the fQRST angle may be due to greater divergence of L - type calcium current among different layers of myocardium and lower density of repolarizing $\mathrm{Kr}$ and Ks currents in females ${ }^{15}$. The incidence of type 2 diabetes mellitus and congestive heart failure was higher in the cohort with higher fQRST angle which was statistically significant. There was increased incidence of hypertension and hyperlipidemia in group 3 but was not statistically significant. The reason for increased angles in hypertension has been attributed to myocardial hypertrophy that alters the ionic channels during the early repolarization phase and increases the collagen interstitial matrix leading to changes in ventricular repolarization ${ }^{16,17}$. The small sample size in our study might have attributed to this finding making it insignificant. Atrial fibrillation was higher in group 3 patients as also in a study by Sawant et $\mathrm{al}^{11}$. The most common and consistent variable for $\mathrm{AF}$ is aging ${ }^{18}$. Other risk factors associated with $\mathrm{AF}$ are hypertension, diabetes mellitus, obesity, chronic obstructive pulmonary disease. The mechanisms involved in genesis of AF are aberrant ventricular repolarization, increased activity of late sodium channels and adrenergic hyperactivity ${ }^{19-21}$. 
A higher fQRST angle was associated with a higher incidence of multi vessel disease ( double and triple vessel) which was in concert with a study done by Palaniswamy et $\mathrm{al}^{22}$.

The length of hospital stay was higher in the higher fQRST angle and lower in the lower range, which was also seen in a study done by Sawant et al. ${ }^{11}$ The fQRST angle may help the clinician to triage patients upfront at arrival and adjudicate resource utilization by contemplating early discharge in lower angle patients, in the meantime providing safe and standard care.It is a well-known fact that higher fQRST angle correlates with sudden cardiac death due to structural aberrations that affect regional pathophysiological changes in ion channels that alter the repolarization sequence that accentuate arrhythmogenicity culminating into malignant ventricular arrhythmias and sudden cardiac death ${ }^{11}$. In this study, in hospital mortality increased as fQRST angle increased and was highest in group 3. A study done by Lingman et al demonstrated that fQRST angle improved prediction of SCD in ACS patients apart from traditional risk factors ${ }^{13}$. For the prediction of mortality after STEMI, fQRST may be of paramount importance.

\section{Limitation}

This study has its limitations. This study was underpowered and the result was negative because the number of patients was relatively low. It was a single-center, retrospective study which may not be representative data. This could have caused selection bias on the assessment and analysis of data which was reflected in the results.

\section{Conclusion}

Diabetes, CHF and AF patients were more likely to have increase in frontal QRST angle. The chance of hospital stay duration significantly increases with increase in frontal QRST angle. Although the in-hospital mortality increased with increase in the frontal QRST angle, it was statistically insignificant. Though being a novel study in our context, further large prospective studies are mandatory to establish this finding.

\section{Acknowledgement \\ None}

\section{Conflict of Interest}

None

\section{References}

1. Pedersen F, Butrymovich V,Kelbæk H, Wachtell K, Helqvist S, Kastrup J, et al. Short and long-term cause of death in patients treated with primary PCI for STEMI. J Am CollCardiol. 2014 Nov;64(20):2101-8. https://doi.org/10.1016/j.jacc.2014.08.037

2. Zhang ZM, Prineas RJ, Case D, Soliman EZ, Rautaharju PM. Comparison of the prognostic significance of the electrocardiographic QRS/T angles in predicting incident coronary heart disease and total mortality. Am J Cardiol. 2007;100(4): 844-9. https://doi.org/10.1016/j. amjcard.2007.03.104

3. Colluoglu T, Tanriverdi Z, Unal B, Ozcan EE, Dursun H, Kaya D. The role of baseline and post-procedural frontal plane QRS-T angles for cardiac risk assessment in patients with acute STEMI. Ann Noninvasive Electrocardiol. 2018;23(5):e12558. https://doi.org/10.1111/anec.12558

4. Desai AD, Yaw TS, Yamazaki T, Kaykha A, Chun S, Froelicher VF.Prognostic significance of quantitative QRS duration. Am J Med. 2006;119(7):600-6. https://10.0.3.248/j. amjmed.2005.08.028

5. Brilakis ES, Mavrogiorgos NC, Kopecky SL, Rihal CC, Gersh BJ, Williams BA, et al. Usefulness of QRS duration in the absence of bundle branch block as an early predictor of survival in non-ST elevation acute myocardial infarction. Am J Cardiol. 2002 May;89(9):1013-8. https://doi.org/10.1016/ s0002-9149(02)02267-1

6. Zabel M, Acar B, Klingenheben T, Franz Mr, Hohnloser SH, Malik M. Analysis of 12-lead T-wave morphology for risk stratification after myocardial infarction. Circulation. 2000 Sep;102(11):1252-7. https://doi.org/10.1161/01. cir.102.11.1252

7. Oehler A, Feldman T, Henrikson CA, Tereshchenko LG. QRS-T Angle: A Review. Ann Noninvasive Electrocardiol. 2014;19(6):534-542. https://doi.org/10.1111/anec.12206

8. Yamazaki T, Froelicher VF, Myers J, Chun S, Wang P. Spatial QRS-T angle predicts cardiac death in a clinical population. Heart Rhythm. 2005;2(1):73-78. https://doi.org/10.1016/j. hrthm.2004.10.040

9. Zang ZM, Prineas RJ, Case D, Soliman EZ, Rautaharju PM. Comparison of the prognostic significance of electrocardiographic QRS/T Angles in predicting incident coronary heart disease and total mortality. Am J Cardiol. 2007;100(5):844-9. https://doi.org/10.1016/j. amjcard.2007.03.104

10. Gungor M, Celik M, Yalcinkaya E, Polat AT, Yuksel UC, Yildirim E, et al. The value of frontal planar QRS-T angle in patients without angiographically apparent atherosclerosis. Med PrincPrac. 2017; 26:125-131. https://doi. org/10.1159/000453267

11. Sawant AC, Bhardwaj A, Srivatsa S, Sridhara S, Prakash M, Kanwar N, et al. Prognostic value of frantal QRS-T angle in predicting survival after primary percutaneous coronary revascularization/coronary artery bypass grafting for STelevation myocardial infarction. IHJ. 2019 Nov;71(6):481-7. https://doi.org/10.1016/j.ihj.2019.09.008

12. Thygesen K, Alpert JS, Jaffe AS, Chaitman BR, Bax JJ, Marrow DA, et al. Fourth Universal Definition of Myocardial Infarction. Journal of American college of cardiology. 2018 Oct; 72(18):2231-64. https://doi.org/10.1016/j. jacc.2018.08.1038

13. Lingman M, Hartford M, Karlsson T, et al. Value of the QRS-T area angle in improving the prediction of sudden cardiac death after acute coronary syndromes. Int J Cardiol. 2016;218:1e11. https://doi.org/10.1016/j.ijcard.2016.05.005

14. Sur S, Han L, Tereshchenko LG. Comparison of sum absolute QRST integral, and temporal variability in depolarization and repolarization, measured by dynamic vectorcardiography approach, in healthy men and women. PLoS One. 2013;8(2):e57175. https://doi.org/10.1371/journal. pone. 0057175

15. Lehmann MH, Yang H. Sexual dimorphism in the electrocardiographic dynamics of human ventricular repolarization: characterization in true time domain. Circulation. 2001;104(1). https://doi.org/10.1161/ hc2601.091738

16. Kleiman RB, Houser SR: Outward currents in normal and hypertrophied feline ventricularmyocytes. Am J Physiol 1989; 256:H1450- H1461. https://doi.org/10.1152/ ajpheart.1989.256.5.H1450

17. Pye MP, Cobbe SM: Mechanisms of ventricular arrhythmias in cardiac failure and hypertrophy. Cardiovasc Res 1992; 26 : 740-750. https://doi.org/10.1093/cvr/26.8.740 
18. Mathew JP, Fontes ML, Tudor IC, Ramsay J, Duke P, Mazer $\mathrm{CD}$, et al. A multicenter risk index for atrial fibrillation after cardiac surgery. JAMA. 2004;291(14):1720-9. https://doi. org/10.1001/jama.291.14.1720

19. Kuo CS, Reddy CP, Munakata K, Surawicz B. Mechanism of ventricular arrhythmias caused by increased dispersion of repolarization. Eur Heart J. 1985;6(Suppl D):63-70. https:// doi.org/10.1093/eurheartj/6.suppl_d.63

20. Song Y, Shryock JC, Belardinelli L. An increase of late sodium current induces delayed afterdepolarizations and sustained triggered activity in atrial myocytes. Am J Physiol Heart Circ Physiol. 2008;294(5):H2031-9. https://doi. org/10.1152/ajpheart.01357.2007

21. Iwasaki YK, Nishida K, Kato T, Nattel S. Atrial fibrillation pathophysiology: implications for management.

Circulation. 2011;124(20):2264-74. https://doi.org/10.1161/ CIRCULATIONAHA.111.019893

22. Palaniswamy C, Singh T, Aronow WS, et al: A planar QRS-T angle $>90$ degrees is associated with multivessel coronary artery disease in patients undergoing coronary angiography. Med SciMonit 2009; 15:MS31-MS34. https://pubmed.ncbi. nlm.nih.gov/19946243/ 